Published in final edited form as:

J Am Chem Soc. 2019 August 28; 141(34): 13562-13571. doi:10.1021/jacs.9b05499.

\title{
The Role of Protein Thermodynamics and Primary Structure in Fibrillogenesis of Variable Domains from Immunoglobulin Light Chains
}

\author{
Enrico Rennella ${ }^{*}, \dagger$, Gareth J. Morgan ${ }^{\ddagger} \S$, Nicholas Yan ${ }^{\ddagger}$, Jeffery W. Kelly ${ }^{\ddagger}$, Lewis E. Kay ${ }^{\star}, \dagger, \|$ \\ tDepartments of Molecular Genetics, Biochemistry and Chemistry, The University of Toronto, \\ Toronto, Ontario, Canada M5S1A8 \\ FDepartments of Molecular Medicine and Chemistry, The Scripps Research Institute, La Jolla, \\ California 92037, United States \\ $\S$ Department of Medicine, Boston University School of Medicine, Boston, Massachusetts 02118, \\ United States \\ "The Hospital for Sick Children, Program in Molecular Medicine, 555 University Avenue, Toronto, \\ Ontario, Canada M5G1X8
}

\begin{abstract}
Immunoglobulin light-chain amyloidosis is a protein aggregation disease that leads to proteinaceous deposits in a variety of organs in the body and, if untreated, ultimately results in death. The mechanisms by which light-chain aggregation occurs are not well understood. Here we have used solution NMR spectroscopy and biophysical studies to probe immunoglobulin variable domain $\lambda \mathrm{V} 6-57 \mathrm{~V}_{\mathrm{L}}$ aggregation, a process that appears to drive the degenerative phenotypes in amyloidosis patients. Our results establish that aggregation proceeds via the unfolded state. We identify, through NMR relaxation experiments recorded on the unfolded domain ensemble, a series of hotspots that could be involved in the initial phases of aggregate formation. Mutational analysis of these hotspots reveals that the region that includes K16-R24 is particularly aggregation prone. Notably, this region includes the site of the R24G substitution, a mutation that is found in variable domains of $\lambda$ light-chain deposits in $25 \%$ of patients. The $\mathrm{R} 24 \mathrm{G} \lambda \mathrm{V} 6-57 \mathrm{~V}_{\mathrm{L}}$ domain aggregates more rapidly than would be expected on the basis of thermodynamic stability alone, while substitutions in many of the aggregation-prone regions significantly slow down fibril formation.
\end{abstract}

\section{Graphical Abstract}

\footnotetext{
*Corresponding Authors: rennella@pound.med.utoronto.ca, kay@ pound.med.utoronto.ca. Supporting Information

The Supporting Information is available free of charge on the ACS Publications website at DOI: 10.1021/jacs.9b05499. Supporting Figures 1-5, including native-state protection factors, $\Delta R$, eff values showing that dispersions measured on the folded state do not correlate with aggregation rates, ThT emission spectra, solvent exchange profiles, and the correlation between experimental errors in $t_{\mathrm{lag}}$ and $\mathrm{k}_{\mathrm{lag}}$ with the values of $t_{\mathrm{lag}}$ and $k_{\mathrm{lag}}$ (PDF)

The authors declare no competing financial interest.
} 


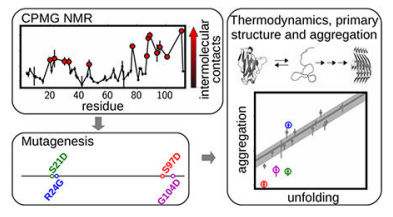

\section{INTRODUCTION}

Immunoglobulin light-chain (LC) amyloidosis (AL) is among the most diagnosed of the systemic amyloid diseases, with an incidence of approximately 10 new cases each year per million people. ${ }^{13}$ In AL, amyloid fibrils derived from LCs secreted from a clonal plasma cell accumulate in a number of different organs and tissues, with heart and kidneys often being the most severely affected. ${ }^{4-6}$ Despite recent improvements in survival resulting from treatments that include chemotherapy and autologous stem cell transplantation, more than half of AL patients do not survive 5 years postdiagnosis. ${ }^{7}$

X-ray crystallography, NMR spectroscopy, and biophysical studies establish that full-length $\kappa$ or $\lambda$ LCs are often dimeric, with each monomer comprising single copies of a variable, $\mathrm{V}_{\mathrm{L}}$, and a constant, $\mathrm{C}_{\mathrm{L}}$, domain with an intervening linker. Each domain, in turn, adopts a $\beta$ sheet-rich structure. ${ }^{8}$ Analysis of amyloid deposits in LC amyloidosis patients reveals that intact full-length LCs can be present, $, 9,10$ and studies using full-length constructs in which a $\lambda$ V6-57 domain was fused to a $\lambda \mathrm{C} 3$ domain showed that fibril formation of full-length LCs occurs when either of the $\mathrm{V}_{\mathrm{L}}$ or $\mathrm{C}_{\mathrm{L}}$ domains is severely destabilized by mutation such that the free energy of domain unfolding is less than $2 \mathrm{kcal} / \mathrm{mol} .{ }^{11}$ More commonly, however, the aggregates comprise just the variable domain derived from aberrant endoproteolysis. ${ }^{9}, 10,12,13$ The importance of the individual $\mathrm{V}_{\mathrm{L}}$ domains to fibril formation is highlighted by recent cryo-EM structures of patient-derived fibrils, indicating that the core of the cross-beta structure is formed by residues from the $\mathrm{V}_{\mathrm{L}}$ subunit. ${ }^{14,15}$ Notably, $\mathrm{V}_{\mathrm{L}}$ domains are much more aggregation-prone than either individual $C_{L}$ domains, full-length LCs, ${ }^{11,16}$ or fulllength LCs with destabilized $C$ domains. ${ }^{11,17}$ In addition, proteolysis at a thrombin cleavage site localized to the $\mathrm{N}$-terminus of the $\mathrm{C}_{\mathrm{L}}$ domain ${ }^{18}$ would lead to the release of $\mathrm{V}_{\mathrm{L}}$ domains that could then form aggregates. Despite a large number of studies, the molecular basis by which fibrillation occurs is not well understood. Fundamental questions remain, such as whether proteolysis is required for aggregation ${ }^{16,19,20}$ or whether fragmentation occurs after the formation of the fibrillar deposits. ${ }^{10}$ Aggregation studies must include, therefore, LC fragments, such as the highly amyloidogenic $\mathrm{V}_{\mathrm{L}}$ domain, in addition to focusing on fulllength LCs.

Here we investigate the aggregation of $\lambda \mathrm{V} 6-57 \mathrm{~V}_{\mathrm{L}}$ domains since immunoglobulin LCs of this family have been observed to be preferentially present in AL patients. ${ }^{21}$ Regions present in the core of the amyloid fibrils formed by this domain and those exposed to solvent are identified through dimethyl sulfoxide-quenched hydrogen/deuterium exchange ${ }^{22}$ experiments. The relationship between protein thermodynamics and fibrillogenesis is investigated, demonstrating that loss of native structure of the $\mathrm{V}_{\mathrm{L}}$ domain is required for fibril formation. Carr-Purcell-Meiboom-Gill (CPMG) relaxation dispersion NMR experiments ${ }^{23,24}$ show that oligomerization can proceed from the unfolded state of the $\mathrm{V}_{\mathrm{L}}$ 
domain via a process that occurs on the millisecond time scale, with regions involved in oligomerization similar to those identified to be aggregation-prone by several prediction algorithms. ${ }^{25}$ A mutagenesis strategy was used to establish which of the oligomerization hotspots identified by CPMG NMR are important for the conversion of unfolded $\mathrm{V}_{\mathrm{L}}$ domains into amyloid fibrils, establishing an important role for sequence comprising strand $\mathrm{B}$ of the native $\mathrm{V}_{\mathrm{L}}$ protein. Notably, this region includes the R24G mutation, found in $25 \%$ of AL patients from this $\lambda$ family, ${ }^{21}$ for which the aggregation rate is shown to be significantly faster than that expected based on thermodynamic stability alone.

\section{RESULTS AND DISCUSSION}

\section{Structural Properties of Native and Fibrillar States of the $V_{L}$ Domain.}

Full length $\kappa$ and $\lambda$ LCs often form dimeric structures, as illustrated by the full length $\mathrm{Cle}^{8}$ LC depicted in Figure 1A, isolated from patient urine. Both $\mathrm{V}_{\mathrm{L}}$ and $\mathrm{C}_{\mathrm{L}}$ domains have a similar fold, comprising stacked $\beta$-sheets stabilized by an intradomain disulfide bridge. The $3 \mathrm{D}$ structure of a representative $\mathrm{V}_{\mathrm{L}}$ domain, the germ line $\lambda \mathrm{V} 6-57 \mathrm{~V}_{\mathrm{L}}$ protein, 6aJL2- $\mathrm{V}_{\mathrm{L}}$, 26,27 is shown in Figure 1B along with its amino acid sequence in Figure 1C. Functional LC genes are created by DNA recombination in B cells, followed by introduction of additional sequence variability through somatic hypermutations. ${ }^{28}$ The sequence conservation for 33 human $\lambda \mathrm{V}_{\mathrm{L}}$ domains ${ }^{29}$ is shown in Figure 1D. Most somatic hypermutation occurs in the complementarity-determining regions (CDRs) that directly contact antigens (Figure 1E) and is not considered in the figure. The prevalent $\beta$-secondary structure of the protein in its native state (Figure 1B,F) differs from the cross- $\beta$-sheet networks present in fibrillar states that have been elucidated in recent solid-state NMR (ssNMR) and cryo-electron microscopy (cryo-EM) amyloid structures from human $\boldsymbol{\kappa}$-type AL-09 $\mathrm{V}_{\mathrm{L}},{ }^{30}$ murine $\boldsymbol{\kappa}$-type MAK33 $\mathrm{V}_{\mathrm{L}}$, ${ }^{31}$ human $\lambda$-type R24G 6aJL2- $\mathrm{V}_{\mathrm{L}}$, and two $\lambda$-type $\mathrm{V}_{\mathrm{L}}$ fibrils extracted from the hearts of AL amyloidosis patients ${ }^{14,15}$ (Figure $1 \mathrm{G}$ ). In particular, the three CDRs that are found in loop regions in the native structure, transition, at least partially, to $\beta$-strand structure in CDR1 and CDR3 ( $\kappa$-type AL-09 $\mathrm{V}_{\mathrm{L}},{ }^{30} \lambda \mathrm{V} 6-57 \mathrm{R} 24 \mathrm{G}$ 6aJL2- $\mathrm{V}_{\mathrm{L}},{ }^{32} \lambda \mathrm{V} 1-44$, and $\lambda \mathrm{V} 6-57$ ex vivo fibril structures, ${ }^{14,15}$ Figure $1 \mathrm{G}$ ) and/or in CDR2 ( $x$-type MAK33 $\mathrm{V}_{\mathrm{L}}{ }^{31}$ and $\lambda \mathrm{V} 1-44$ ex vivo fibril structure, ${ }^{14}$ Figure $\left.1 \mathrm{G}\right)$. The identified $\beta$-strand regions are not identical in these ssNMR- and cryo-EM-derived structures of amyloid fibrils, indicating that $\mathrm{V}_{\mathrm{L}}$ domains can form different fibrillar structures, likely depending on the relative distribution of aggregation propensities within aggregation-prone regions. Alternatively, there may be one wellconserved aggregation-driving region that triggers formation of a fibrillar nucleus followed by propagation of cross- $\beta$-structure in a pattern that is sequence-specific.

In an effort to confirm the regions of 6aJL2- $\mathrm{V}_{\mathrm{L}}$ forming regular secondary structures in the fibril, as very recently identified by Lecoq et al. ${ }^{32}$ for the R24G mutant, we used the dimethyl sulfoxide (DMSO)-quenched hydrogen/deuterium exchange method. ${ }^{22,33}$ In this approach fully amide protonated fibers are exposed to $\mathrm{D}_{2} \mathrm{O}$ solvent for a defined time to allow exchange of the amides which are not stably hydrogen bonded. After quenching the exchange via lyophilization and subsequent dissolution of the fibril in denaturing DMSO, ${ }^{1} \mathrm{H}-{ }^{15} \mathrm{~N}$ HSQC spectra are acquired to quantify the intensities of the amide sites, and hence the remaining amide protonation. The drop in intensities of amide correlations in HSQC data 
sets following $2 \mathrm{~h}$ of incubation in deuterated buffer, reporting on solvent exchange in the fiber, is plotted against residue number in Figure 1H. The largest loss of signal is observed for amides in the middle of the protein sequence, between residues R40 and G65. This region, therefore, does not form a rigid, hydrogen-bonded structure in the fiber, but rather is sufficiently flexible so that approximately half of the amide protons exchange with deuterons over a $2 \mathrm{~h}$ period. Ratios larger than 0.8 are generally observed for T17-Q39 and S66-F102; amide hydrogens in these regions are stabilized through hydrogen bonding and are therefore not available to exchange with solvent. Values between 0.6 and 0.8 are measured for the Nand $\mathrm{C}$-terminal regions. These amides may be part of the cross- $\beta$-sheet network, but undergo some hydrogen exchange through solvent penetration and local transient unfolding at the edge of the $\beta$-strands. The overall protection pattern is consistent with the secondary structure recently reported by Lecoq et al. of amyloid fibrils from R24G 6aJL2- $\mathrm{V}_{\mathrm{L}}{ }^{32}$ (structures 3 and 4 in Figure 1G), in which residues P45-P60 are mostly unassigned due to structural disorder in the fibrils, and with a recently published cryo-EM structure of another $\lambda$ V6-57 LC ${ }^{15}$ (structure 5 in Figure 1G), where amino acids extending from Q38-G65 were shown to be structurally disordered. It is also compatible with the quaternary cross- $\beta$-sheet structure of the AL-09 $\mathrm{V}_{\mathrm{L}}$ fiber $^{30}$ (structure 1 in Figure 1G), showing $\beta$-strands in the $\mathrm{N}$ and C-termini.

\section{Loss of Native Structure Is Required for Aggregation.}

NMR-detected native-state hydrogen exchange experiments were acquired for wild-type 6aJL2- $\mathrm{V}_{\mathrm{L}}$ under EX2 conditions to probe the stability of single structural elements of the domain. ${ }^{34}$ The profile of residue-specific protection factors (the ratio of "intrinsic", residuespecific exchange rates measured on unstructured peptides ${ }^{35}$ to rates extracted from the protein of interest) shows higher protection in $\beta$-strand regions that are most buried in the core of the immunoglobulin fold (maroon in Figure S1), in particular strands B, C, D, E, and F. The largest protection factors, averaging approximately 10000 , directly report on global unfolding of the domain. ${ }^{36}$ With the aim of generating several protein variants covering a wide range of thermodynamic stability, 12 moderately conservative single-point mutations were introduced into 6aJL2- $\mathrm{V}_{\mathrm{L}}$ (Figure $2 \mathrm{~A}$ ), and native-state hydrogen exchange experiments were recorded for each mutant. The exchange time-course for three representative amide groups, I20 ( $\beta$-strand B), Y37 ( $\beta$-strand C), and Y89 ( $\beta$-strand F), are shown in Figure $2 \mathrm{~B}$ for three $6 \mathrm{aJL} 2-\mathrm{V}_{\mathrm{L}}$ sequences including germ line ${ }^{26,27}$ (also referred to as wild-type, WT, in what follows), and $\mathrm{V}_{\mathrm{L}}$ domains where $\mathrm{I} 29$ was substituted by either valine (I29V) or alanine (I29A). Each amide group of residues I20, Y37, and Y89 reports on hydrogen exchange occurring through global unfolding, as these are among the slowest exchanging amides in the domain (Figure S1). Not surprisingly, among these three $\mathrm{V}_{\mathrm{L}}$ domains the protein with the fastest hydrogen exchange is the mutant with the largest introduced cavity, I29A, followed by I29V, while the amides of the WT protein exchange more slowly.

The 12 mutants and the WT protein were assessed with regard to their kinetics of aggregation. The thioflavin $\mathrm{T}(\mathrm{ThT})^{37}$ fluorescence-based aggregation time courses are shown in Figure $2 \mathrm{C}$ for the three representative $6 \mathrm{aJL2}-\mathrm{V}_{\mathrm{L}}$ variants considered above, WT, $\mathrm{I} 29 \mathrm{~V}$, and I29A. A correlation is observed between hydrogen exchange rates and the kinetics 
of aggregation: the variant with the fastest hydrogen exchange, I29A, also displays the fastest ThT-based aggregation kinetics, while the WT 6aJL2- $\mathrm{V}_{\mathrm{L}}$ domain exhibits the slowest hydrogen exchange and aggregation rates. The correlation noted for WT, I29V, and I29A is observed for all of the $6 \mathrm{aJL} 2-\mathrm{V}_{\mathrm{L}}$ variants and for two additional $\lambda \mathrm{V} 6-57 \mathrm{~V}_{\mathrm{L}}$ proteins derived from patients, JTO and WIL, ${ }^{38}$ as illustrated in Figure 2D. Here the lag rate, $k_{\text {lag }}(y$-axis), defined as the inverse of the duration of the lag phase (Figure $2 \mathrm{C}$ ), is correlated with the fraction of globally unfolded protein at $37^{\circ} \mathrm{C}, \mathrm{pH} 6.4, f_{\mathrm{U}}$ ( $x$-axis), calculated as the inverse of the average protection factor for the most protected amides. Values of $f_{\mathrm{U}}$ were obtained assuming EX2 exchange kinetics. This was verified for the least stable mutant, V34A, where the $f_{\mathrm{U}}$ value at $37^{\circ} \mathrm{C}$ measured by thermal melting as probed by intrinsic fluorescence, 0.21 \pm 0.02 , was found to be in excellent agreement with $f_{\mathrm{U}}$ from hydrogen exchange, $0.19 \pm 0.03$ (Figure 2E).

To establish whether the mutant proteins form similar fibril structures, we repeated the dimethyl sulfoxide-quenched hydrogen/deuterium exchange experiments discussed above for a pair of mutants, S31P and S97P, where the Pro mutations might be expected to significantly perturb the fibril structures, as proline residues are $\beta$-strand breakers. Notably, germ line-like patterns of hydrogen exchange were observed in the S31P and S97P fibrils (Figure 2F). The overall structure of the fibril is therefore tolerant of changes in local structure, as has been observed by Brumshtein et al. ${ }^{39}$

To further probe the relationship between thermal unfolding and fibrillogenesis, we measured the thermal melting of five 6aJL2- $\mathrm{V}_{\mathrm{L}}$ sequences (WT, I29V, V34A, V59A, and $\mathrm{I} 67 \mathrm{~V})$ by intrinsic fluorescence and then compared the measured $f_{\mathrm{U}}$ values with aggregation rates at a pair of temperatures, 44 and $55^{\circ} \mathrm{C}$. Since aggregation assays were done at $\mathrm{pH} 7.4$ in phosphate-buffered saline, the melting curves were also obtained under these conditions, which leads to decreased thermodynamic stability relative to samples dissolved in $\mathrm{D}_{2} \mathrm{O}$ solvent (Figure $2 \mathrm{E} ; \mathrm{D}_{2} \mathrm{O}$ solvent was necessary for hydrogen exchange measurements). The relative ranking of thermodynamic stability for the five proteins is the same as measured by hydrogen exchange, WT > I67V > I29V > V59A > V34A (compare Figure 2D and G). At $44{ }^{\circ} \mathrm{C}$, WT and I67V domains, which are least prone to aggregation, have the lowest $f_{\mathrm{U}}$ values (Figure $2 \mathrm{H}$ ), while at $55^{\circ} \mathrm{C}$ the aggregation rates are more similar between the five proteins with WT and I67V still aggregating slightly more slowly than the others (Figure $2 \mathrm{I})$. The difference in the aggregation rates between the five $6 \mathrm{aJL} 2-\mathrm{V}_{\mathrm{L}}$ variants is flattened upon increasing the temperature where $f_{\mathrm{U}}$ values become uniformly larger; for example, the aggregation of V34A is 21-fold, 4-fold, and 1.5-fold faster than the germ line at 37, 44, and $55^{\circ} \mathrm{C}$, respectively. This is consistent with global unfolding leading to aggregation of the variants examined. The increase in temperature above the melting points of all the domains leads to similar populations of their globally unfolded states (close to an upper limit of $100 \%$ ) and, hence, a parallel reduction of native and partially unfolded states. The net result is a partial equalization of the rates of fibril formation.

\section{Polymerization-Prone Regions Mapped by Solution NMR and Prediction Tools.}

The results described above are consistent with the hypothesis that loss of native structure is required for amyloid formation, as has been observed for other proteins. ${ }^{40-42}$ However, 
assembly into fibrils likely requires formation of specific, favorable, intermolecular contacts in order to overcome the entropic barrier to fibrillation. LCs with different sequences may have different propensities to self-associate in the unfolded state, which may affect their ability to aggregate and cause disease. We therefore performed ${ }^{15} \mathrm{~N}$ CPMG relaxation dispersion experiments to identify initial oligomerization events that might be responsible for the conversion of soluble $\mathrm{V}_{\mathrm{L}}$ domains into amyloid fibrils. These NMR-based spinrelaxation experiments quantify decay rates of NMR signals, $R_{2, \text { eff }}$, during a fixed evolution period where the frequency of application of chemical shift refocusing pulses, $v_{\mathrm{CPMG}}$, is varied. This class of NMR experiment is sensitive to rare oligomerization events occurring on the millisecond time scale, ${ }^{43,44}$ wherein the population of the resulting oligomer can be as low as $\sim 0.5 \% .{ }^{45}{ }^{15} \mathrm{~N} \mathrm{CPMG}$ experiments ${ }^{23}$ recorded at $25{ }^{\circ} \mathrm{C}$ on the native state of wildtype 6aJL2- $\mathrm{V}_{\mathrm{L}}$ indicated the presence of native oligomers as previously observed for JTO$\mathrm{V}_{\mathrm{L}}$ and WIL- $\mathrm{V}_{\mathrm{L}} \cdot{ }^{11}$ Perturbation of this native oligomerization through the introduction of mutations in the $\mathrm{V}_{\mathrm{L}}-\mathrm{V}_{\mathrm{L}}$ dimerization interface did not influence fibril formation, with the lag rate $k_{\text {lag }}$ solely determined by the fraction of unfolded protein, $f_{\mathrm{U}}$ (Figure $\mathrm{S} 2$ ), in agreement with the results in Figure 2. ${ }^{15} \mathrm{~N} \mathrm{CPMG}$ experiments were therefore recorded at $55^{\circ} \mathrm{C}$ for the globally unfolded state of three $\lambda \mathrm{V} 6-57 \mathrm{~V}_{\mathrm{L}}$ proteins, including those derived from the germ line 6aJL2, WIL, and JTO. Nonflat CPMG profiles were observed for several ${ }^{15} \mathrm{~N}$ probes in each of the three sequences considered, indicating that the domains undergo conformational exchange involving one or more sparsely populated states. Notably, the size

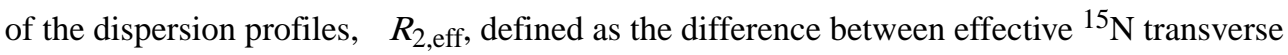
relation rates at the lowest $(\sim 30 \mathrm{~Hz})$ and the highest $(1 \mathrm{kHz})$ CPMG field strengths used, $\Delta R_{2, \text { eff }}=R_{2, \text { eff }}(30 \mathrm{~Hz})-R_{2, \text { eff }}(1 \mathrm{kHz})$, was dependent on protein concentration, as illustrated with CPMG curves for L111 in WT 6aJL2, WIL, and JTO $\mathrm{V}_{\mathrm{L}}$ domains, Figure $3 \mathrm{~A}$. As $\Delta \mathrm{R}_{2 \text {,eff }}$ increases with protein concentration in all cases, the population of particles in solution is highly skewed toward the monomer. The dispersion profiles could not be globally fitted using a model of exchange involving a single interconversion between monomer and dimer. This suggests that each site experiences independent oligomerization events, most likely a mixture between on- and off-pathway processes with respect to fibril formation, or that each amide is sensitive to a different stage of early fibril formation. Individual residue fits of CPMG profiles indicate exchange rates of approximately $1000 \mathrm{~s}^{-1}$, although the populations of the interconverting species could not be well defined by the data, pointing to a complex exchange mechanism, as would be expected for a protein domain with multiple regions that are available for oligomerization. It is worth noting that this complexity is not the result of contributions from the folding/unfolding reaction. Even at $55^{\circ} \mathrm{C}$ separate peaks are observed for the C-terminal residue, G112, of both 6aJL2- $\mathrm{V}_{\mathrm{L}}$ and JTO- $\mathrm{V}_{\mathrm{L}}$ that derive from native and unfolded states (see Materials and Methods), implying that the folding equilibrium occurs on a time scale that is much slower than the exchange process(es), consistent with folding rates reported in the literature. ${ }^{16}$ Therefore, the folding equilibrium will not contribute to the dispersion profiles measured from the unfolded state in this study.

The concentration dependence of $\Delta R_{2, \text { eff }}$ is plotted as a function of protein sequence in Figure 3B. The red circles in these profiles highlight those residues with the largest changes in $\Delta R_{2, \text { eff }}$, corresponding to "oligomerization hotspots". Regions predicted by the program AMYLPRED 25 are plotted as squares below each sequence in Figure 3B. The agreement 
between experimental and predicted data is good, with the great majority of red circles within predicted regions. Most discrepancies are found between positions 85 and 100, where the prediction algorithms underestimate the potential for polymerization that is observed by CPMG NMR. This may be the result of the intramolecular disulfide bridge connecting C22 and C91 that would bring the 85-100 region proximal to residues on the other end of the disulfide bond, thereby influencing aggregation propensities. The effect of the disulfide bond is not taken into account in the prediction program. Significant precipitation of the protein occurred during the acquisition of CPMG NMR data (1 day), especially for the more concentrated samples and for wild-type $6 \mathrm{aJL} 2-\mathrm{V}_{\mathrm{L}}$. These precipitates were ThT-positive (Figure S3), indicating that pathways leading to fibril formation are present even in the absence of agitation.

\section{Important Regions for Fibril Formation.}

Our CPMG data recorded on a series of unfolded $\mathrm{V}_{\mathrm{L}}$ domains suggest multiple regions with the propensity to polymerize and hence multiple oligomerization processes likely occurring on separate time scales. In order to assess the relative importance of each polymerizationprone region, as predicted by AMYLPRED2 and indicated in Figure 3B, we generated a series of $106 \mathrm{aJL} 2-\mathrm{V}_{\mathrm{L}}$ mutants where each of these regions was modified by replacement of a single amino acid with aspartate. The mutations are made to solvent-exposed side chains in order to avoid destabilization of the native states of the domains. We also considered the somatic mutation $\mathrm{R} 24 \mathrm{G},{ }^{21}$ which removes a polar side chain in the aggregation-prone 16-24 region. The location of each of the mutations along the protein sequence is shown in Figure $4 \mathrm{~A}$, together with the predicted aggregation regions using AMYLPRED2. In addition, polymerization-prone regions identified by CPMG NMR in any of the WT 6aJL2, WIL, and JTO $\mathrm{V}_{\mathrm{L}}$ domains discussed above are also indicated. Aggregation assays monitored by ThT fluorescence establish that all the mutants form amyloid fibrils, but they have different aggregation kinetics (Figure 4B, black symbols). The aggregation data for $6 \mathrm{aJL} 2-\mathrm{V}_{\mathrm{L}}$ variants S21D ( $p$-value $=0.023$, where the $p$-value is calculated for the null hypothesis that the aggregation kinetics are not different for the new set of 11 variants), $\mathrm{R} 24 \mathrm{G}$ ( $p$-value $=$ $0.0007), \mathrm{Q} 92 \mathrm{D}(p$-value $=0.040), \mathrm{S} 97 \mathrm{D}(p$-value $=0.026)$, and G104D $(p$-value $=0.050)$ deviate from the linear $k_{\text {lag }}$ vs $f_{\mathrm{U}}$ profile calculated in Figure $2 \mathrm{D}$ that made use of more conservative mutations (Figure 4B, solid gray region). For the mutants localized to aggregation hotspots $k_{\text {lag }}$ rates are either significantly slower (S21D, S97D, G104D) or faster (R24G, Q92D) than what would be predicted based purely on thermodynamic stability. Notably, these aggregation assays emphasize the important role of the K16-R24 region, as introduction of a charge (S21D) reduces the rate of fibril formation, while removal of a charge (R24G) enhances the kinetics of aggregation, despite the fact that these two proteins have similar thermodynamic stabilities, as measured by hydrogen exchange of the most slowly exchanging amides (Figure 4C, Figure S4). The slower aggregation profiles for some of the Asp substitutions in aggregation-prone regions, such as for S21D, are not surprising, as the introduction of a charge would be expected to decrease formation of fibers if indeed the perturbed region is critical for this process. The situation for R24G, where the aggregation rate is increased, is interesting, as this is a somatic mutation found in $25 \%$ of $\mathrm{AL}$ patients for this $\lambda$ family. ${ }^{21}$ Our results show that this mutation is linked to AL not only because of the reduced thermodynamic stability ${ }^{26}$ relative to WT but also from removal of 
the arginine side chain, which increases the aggregation propensity at the level of the primary structure. Position 24 is one hotspot for somatic mutation linked to AL since it is a hypervariable position of the $\mathrm{V}_{\mathrm{L}}$ domain yet adjacent to a very conserved aggregation-prone region (Figure 1D). We do not currently have an explanation for why the Q92D substitution increases the kinetics of aggregation, except that it may reduce off-pathway excursions.

Brumshtein et al. ${ }^{39}$ have carried out a similar mutagenesis study to evaluate regions in $\mathrm{V}_{\mathrm{L}}$ domains that drive aggregation, using a different set of mutations than the Asp substitutions considered here. In particular, two mutations, in combination, L76P and V100P+V101P $+\mathrm{F} 102 \mathrm{P}+\mathrm{G} 103 \mathrm{P}$, were found to inhibit fibril formation in the VL2-8-J1 domain. In our study regions surrounding residues 76 and 100-103 were found to be aggregation prone on the basis of CPMG relaxation experiments. However, we failed to observe a significant effect for the introduction of aspartate residues at positions 77 and 102, although some delay in the aggregation was observed for mutations at position 97 or 104. Differences between the two studies may arise from the different mutagenesis approaches used, coupled with the different $\mathrm{V}_{\mathrm{L}}$ proteins considered. Nevertheless, both studies establish that although the effect of a given mutation on the rate of aggregation depends on the region where the mutation is introduced, with some sites more important than others, amyloid formation likely involves an interplay between several sites. The opposing views of a single sequence exclusively responsible for the aggregation or that the driving force is nonspecific are both oversimplifications.

In summary, our studies of the immunoglobulin $\lambda \mathrm{V} 6-57 \mathrm{~V}_{\mathrm{L}}$ domain, which is preferentially found in aggregates from AL patients, ${ }^{21}$ establish that global unfolding is an obligatory step in fibril formation, as a linear correlation between aggregation rate and fraction unfolded $\mathrm{V}_{\mathrm{L}}$ domain was observed. Aggregation hotspots are established through a ${ }^{15} \mathrm{~N}$ relaxation dispersion analysis performed as a function of protein concentration, identifying, in particular, residues within the K16-R24 fragment. Hydrogen exchange profiles of a number of variants of the $\lambda \mathrm{V} 6-57 \mathrm{~V}_{\mathrm{L}}$ sequence including the germ line, S31P and S97P, show that similar fibrillar structures are obtained, with protection for the first 40 and last 50 residues, while the region encompassing R40-P60 remains flexible. Notably, the secondary structural propensities observed here are similar to those found in AL-09 $\mathrm{V}_{\mathrm{L}}{ }^{30}$ and $\mathrm{R} 24 \mathrm{G}$ 6aJL2- $\mathrm{V}_{\mathrm{L}}{ }^{32}$ fibers and in the cryoEM structure of a $\lambda \mathrm{V} 6-57 \mathrm{LC}$ fibril, ${ }^{15}$ but differ from MAK33 $\mathrm{V}_{\mathrm{L}}$ domain fibrils and the cryoEM structure of a $\lambda \mathrm{V} 1-44 \mathrm{LC}$ fibril. ${ }^{14}$ This emphasizes the importance of studies on a wide range of light-chain sequences so as to establish the molecular determinants that are responsible for their aggregation and, ultimately, develop the relevant pharmaceuticals that can eliminate the process. ${ }^{46}$

\section{MATERIALS AND METHODS}

\section{Sequence Conservation.}

The sequence conservation for the $\lambda \mathrm{V}_{\mathrm{L}}$ domains, as calculated using the program $\mathrm{CompBio}^{47}$ and shown in Figure 1D, was based on an analysis that included 33 reviewed germ line IGLV sequences and the five functional IGLJ sequences present in the UniProt database. ${ }^{29}$ Note that the joining of single IGLV and IGLJ sequences by DNA rearrangement during the differentiation of B cells from hematopoietic stem cells leads to 
the formation of a mature $\lambda \mathrm{V}_{\mathrm{L}}$ domain. ${ }^{48}$ Residue-by-residue values of conservation were calculated according to the Shannon entropy of residues with a window size equal to zero. 47,49

\section{Protein Production.}

$\lambda \mathrm{V} 6-57 \mathrm{~V}_{\mathrm{L}}$ domains were expressed in BL21(DE3) E. coli cells using a pET-22 plasmid with a pelB leader for periplasmic expression. Protein production and purification were as previously described. ${ }^{11}$ The sequence of the germ line $\lambda \mathrm{V} 6-57 \mathrm{~V}_{\mathrm{L}}$ protein, $6 \mathrm{aJL} 2-\mathrm{V}_{\mathrm{L}},{ }^{26,27}$ is the IGLV6-57*01 allele in the IMGT repertoire. ${ }^{50}$

\section{NMR Experiments.}

All NMR experiments were performed on a Bruker Avance III HD $14.1 \mathrm{~T}$ spectrometer equipped with a cryogenically cooled, $\mathrm{x}, \mathrm{y}, \mathrm{z}$ pulsed-field gradient triple-resonance probe. Details of individual experiments are described in what follows.

1. Dimethyl Sulfoxide-Quenched Hydrogen/Deuterium Exchange.-Fibrils of 6aJL2- $\mathrm{V}_{\mathrm{L}}$ were formed by incubation of $20-50 \mathrm{~mL}$ solutions containing $20 \mu \mathrm{M} \mathrm{U}-{ }^{15} \mathrm{~N}$ protein, phosphate-buffered saline (PBS) pH 7.4, and $5 \mathrm{mM} \mathrm{NaN}_{3}$, in a $1 \mathrm{~L}$ flask with shaking ( $250 \mathrm{rpm})$ over 3 days, $37^{\circ} \mathrm{C}$. At the end of this period the solution was split into two tubes, and fibrils were collected by centrifugation at $15000 \mathrm{~g}$. Fibrils were then resuspended into $10 \mathrm{~mL}$ of $50 \mathrm{mM}$ BisTris, pH 6.4 buffer, either $\mathrm{H}_{2} \mathrm{O}$ based (reference sample) or $\mathrm{D}_{2} \mathrm{O}$ based (exchange sample). Fibrils for the reference sample were collected and washed using the following protocol: centrifugation at $15000 \mathrm{~g}$ and $4{ }^{\circ} \mathrm{C}$, resuspension in $5 \mathrm{~mL}$ of ice-cold Milli-Q $\mathrm{H}_{2} \mathrm{O}$, centrifugation at $15000 \mathrm{~g}$ and $4{ }^{\circ} \mathrm{C}$, resuspension in $1 \mathrm{~mL}$ of ice-cold Milli-Q $\mathrm{H}_{2} \mathrm{O}$, and freeze-drying. Fibrils used for the exchange measurements were collected after $2 \mathrm{~h}$ of incubation in deuterated buffer $\left(23^{\circ} \mathrm{C}\right)$ and washed using the same protocol as described above for the reference sample, except that ice-cold $\mathrm{D}_{2} \mathrm{O}$ was used in the two resuspension steps. An exchange time of $2 \mathrm{~h}$ is optimal since incubation for longer times does not lead to further exchange for the faster exchanging amides (residues 40-65), with $I / I(0 \mathrm{~h})$ values of approximately 0.5 , while all other amides continue to exchange toward a constant plateau value of approximately 0.5 , therefore reducing the dynamic range of the experiment. For NMR detection, lyophilized samples were dissolved in $95 \%$ DMSO- $d_{6}, 5 \%$ $\mathrm{D}_{2} \mathrm{O}$, and $50 \mathrm{mM}$ sodium dichloroacetate, $\mathrm{pD} 5$, and acquisition of ${ }^{1} \mathrm{H},{ }^{15} \mathrm{~N}$ HSQC spectra was started immediately at $10{ }^{\circ} \mathrm{C}$. The sample $\mathrm{pH}$ and temperature for NMR acquisition are optimal to minimize the hydrogen exchange reaction during the experiments, ${ }^{51}$ so that the amide proton occupancies depend only on the hydrogen exchange that occurred in the fibrillar state. The experiment for the WT protein was performed in duplicate, and the error bars in Figure $1 \mathrm{H}$ indicate differences between the two replicates. Peak assignments were obtained using (HB)CBCA(CO)NNH, HNCACB, HNCO, $\mathrm{HN}(\mathrm{CA}) \mathrm{CO}$, and $\mathrm{HNN}$ spectra $^{52}$ recorded on a uniformly ${ }^{13} \mathrm{C},{ }^{15} \mathrm{~N}$-labeled sample of $6 \mathrm{aJL} 2-\mathrm{V}_{\mathrm{L}}$ with a protein concentration of $1.1 \mathrm{mM}$ in $95 \%$ DMSO- $d_{6}, 5 \% \mathrm{D}_{2} \mathrm{O}$, and $50 \mathrm{mM}$ sodium dichloroacetate, $\mathrm{pH} 5$.

2. Native-State Hydrogen Exchange.- $\lambda \mathrm{V} 6-57 \mathrm{~V}_{\mathrm{L}}$ domain samples, prepared as described above, were desalted by dialysis against Milli- $\mathrm{Q} \mathrm{H}_{2} \mathrm{O}$ and freeze-dried.

Subsequently they were dissolved in $\mathrm{D}_{2} \mathrm{O}$-based buffer comprising $20 \mathrm{mM}$ sodium citrate, 
pD 5, and acquisition of a series of ${ }^{1} \mathrm{H},{ }^{15} \mathrm{~N}$ HSQC spectra at $37{ }^{\circ} \mathrm{C}$ was started immediately. The concentration of the protein used in the study ranged between 0.12 and $0.45 \mathrm{mM}$.

Protection factors were calculated as $\mathrm{PF}=k_{\mathrm{rc}} / k_{\mathrm{ex}}$, where $k_{\mathrm{rc}}$ is the residue-specific value of the intrinsic rate of hydrogen exchange for an unfolded peptide ${ }^{35} k_{\mathrm{rc}}$ rates were calculated using the Web tool at http://hx2.med.upenn.edu/download.html. Values of $f_{\mathrm{U}}$ were calculated as the reciprocal of the average protection factors for the most protected amides in each domain (for example, maroon-colored residues in Figure S1 highlighting the WT protein).

3. CPMG Experiments. $-{ }^{15} \mathrm{~N}$ CPMG experiments were recorded on $\mathrm{U}_{-}{ }^{15} \mathrm{~N}$ labeled proteins dissolved in buffer comprising $50 \mathrm{mM}$ BisTris, pH 6.4, $1 \mathrm{mM} \mathrm{EDTA,} 5 \mathrm{mM} \mathrm{NaN}_{3}$, and $90 \% \mathrm{H}_{2} \mathrm{O} / 10 \% \mathrm{D}_{2} \mathrm{O}$. Protein concentrations varied from 0.2 to $1.2 \mathrm{mM}$. Dispersion profiles were acquired by measuring the variation of effective transverse relaxation rates of in-phase ${ }^{15} \mathrm{~N}$ magnetization, $R_{2, \text { eff }}$, as a function of the number of refocusing pulses applied during a constant-time relaxation interval, $T$, of $35 \mathrm{~ms},{ }^{23} R_{2, \text { eff }}=1 / T \ln \left(I_{0} / I\right)$, where $I$ is the intensity of a peak at a given, nonzero, value of $\nu_{\mathrm{CPMG}}$ and $I_{\mathrm{O}}$ is the corresponding intensity when $T=0$. A $17 \mathrm{kHz}{ }^{1} \mathrm{H}$ continuous-wave decoupling field was applied during the constant-time interval. ${ }^{53}$ The CPMG frequency, $v_{\mathrm{CPMG}}$, is given by $1 /(2 \delta)$, where $\delta$ is the delay between successive refocusing pulses. ${ }^{54} \mathrm{~A}$ total of $18-232 \mathrm{D}$ planes were recorded with different $v_{\mathrm{CPMG}}$ values, between 30 and $1000 \mathrm{~Hz}$, with three repeats for error analysis; 55 in addition a reference plane was recorded without the constant-time relaxation interval to obtain $I_{\mathrm{o}}$ values. All CPMG experiments were recorded at $55^{\circ} \mathrm{C}$, where proteins were predominantly unfolded. A small population of the native state could be quantified on the basis of the pair of peaks observed for the C-terminal residue G112, corresponding to the native and unfolded states, with peak intensities in the reference plane indicating the presence of $\sim 25 \%$ and $\sim 10 \%$ of folded domains for $6 \mathrm{aJL} 2-\mathrm{V}_{\mathrm{L}}$ and JTO- $\mathrm{V}_{\mathrm{L}}$, respectively. No residual population of the native state could be detected for WIL- $\mathrm{V}_{\mathrm{L}}$, in agreement with its lower thermodynamic stability. ${ }^{38}$ Furthermore, since sample precipitation was observed during the course of data acquisition, especially for the more concentrated samples, determination of protein concentration was not straightforward and was done as follows: Two short $(8 \mathrm{~min}){ }^{1} \mathrm{H},{ }^{15} \mathrm{~N}$ HSQC spectra were recorded before and after the CPMG experiments. The change in intensity between the two spectra was found to be small (less than $10 \%$ ) for samples in the $0.2-0.3 \mathrm{mM}$ concentration range but larger (up to $40 \%$ ) for the more concentrated samples. Therefore, for the less concentrated samples, absorbance measurements at $280 \mathrm{~nm}$ were used to estimate the total protein concentrations, and the concentration of the unfolded state was estimated according to the intensity of the two peaks for G112 in the reference plane. For more concentrated samples the average concentration of the unfolded state during the course of the CPMG experiments was estimated by comparing the intensity of the G112 peak in the reference plane with that of the less concentrated samples that do not aggregate over time. Note that all the planes comprising the pseudo-3D dispersion data set (different $v_{\mathrm{CPMG}}$ values), including the reference plane, are acquired in an interleaved manner. Thus, the intensity of peaks in the reference plane provides an estimate for the average concentration of protein over the course of the experiment. Spectral assignments for each domain were obtained using $(\mathrm{HB}) \mathrm{CBCA}(\mathrm{CO}) \mathrm{NNH}, \mathrm{HNCACB}$, $\mathrm{HNCO}, \mathrm{HN}(\mathrm{CA}) \mathrm{CO}$, and $\mathrm{HNN}$ data sets. ${ }^{52}$ 


\section{Fibril Formation Assays.}

Solutions (100 $\mu \mathrm{L}$ ) containing $10 \mu \mathrm{M}$ protein and $1 \mu \mathrm{M}$ ThT were incubated at 37, 44, or $55^{\circ} \mathrm{C}$ in black, clear-bottomed, untreated 96-well plates (Figures 2C,D and 4B,D). Plates were covered by transparent film and a lid to reduce evaporation. ThT fluorescence was measured with a plate reader, with excitation at $440 \mathrm{~nm}$ and emission at $480 \mathrm{~nm}$. The assays were done in PBS, pH 7.4, with agitation at $1000 \mathrm{rpm}$. Errors in $t_{\text {lag }}=1 / k_{\text {lag }}$ values were calculated from multiple aggregation measurements (at least 6 repeats), with the error in $k_{\text {lag }}, \Delta k_{\text {lag }}$, given by $\Delta k_{\text {lag }}=\Delta t_{\text {lag }} k_{\text {lag }}{ }^{2}$. Since the experimental errors in $t_{\text {lag }}$ are proportional to $t_{\text {lag }}$ values (Figure S5), the shaded area in Figure 4B is calculated as $k_{\text {lag,fit }}(1 \pm a)$ where $a=\left\langle\left[\left(k_{\text {lag,expt }}-k_{\text {lag,fit }}\right) / k_{\text {lag,fit }}\right]^{2}\right\rangle^{0.5}$, and \langle\rangle refers to the average over experimental data points.

\section{Intrinsic Fluorescence.}

Fluorescence spectra of samples at protein concentrations of $0.02 \mathrm{mM}$ were acquired with a PTI QuantaMaster 80 spectrofluorometer using an excitation wavelength of $280 \mathrm{~nm}$. The excitation and emission slit widths were set respectively to 2 and $4 \mathrm{~nm}$. A step size of $2 \mathrm{~nm}$ and an integration time of $2 \mathrm{~s}$ were used. The acquisition of the spectrum at each temperature was started $2 \mathrm{~min}$ after the cuvette had reached the desired temperature. The emission between 300 and $400 \mathrm{~nm}$ as a function of temperature was fit to a two-state equation for thermal denaturation. ${ }^{56}$

\section{Supplementary Material}

Refer to Web version on PubMed Central for supplementary material.

\section{ACKNOWLEDGMENTS}

This work was supported by grants from the Canadian Institutes of Health Research (CIHR) and the Natural Sciences and Engineering Research Council of Canada (to L.E.K.) and by NIH grant DK46335 and the Skaggs Institute for Chemical Biology (J.W.K.). L.E.K. holds a Canada Research Chair in Biochemistry.

\section{REFERENCES}

(1). Quock TP; Yan TJ; Chang E; Guthrie S; Broder MS Epidemiology of AL amyloidosis: a realworld study using US claims data. Blood Adv. 2018, 2 (10), 1046-1053. [PubMed: 29748430]

(2). Hemminki K; Li XJ; Forsti A; Sundquist J; Sundquist K, Incidence and survival in non-hereditary amyloidosis in Sweden. BMC Public Health 2012, 12, DOI: 10.1186/1471-2458-12-974 [PubMed: 22221851]

(3). Magy-Bertrand N; Dupond JL; Mauny F; Dupond AS; Duchene E; Gil H; Kantelip B; Members C Incidence of amyloidosis over 3 years: the AMYPRO study. Clin Exp Rheumatol 2008, 26 (6), 1074-1078. [PubMed: 19210872]

(4). Rosenzweig M; Landau H Light chain (AL) amyloidosis: update on diagnosis and management. J. Hematol. Oncol 2011, 4, 47. [PubMed: 22100031]

(5). Milani P; Merlini G; Palladini G Light Chain Amyloidosis. Mediterr J. Hematol Infect Dis 2017, 10 (1), e2018022.

(6). Falk RH; Alexander KM; Liao R; Dorbala S AL (Light-Chain) Cardiac Amyloidosis: A Review of Diagnosis and Therapy. J. Am. Coll. Cardiol 2016, 68 (12), 1323-41. [PubMed: 27634125]

(7). Wechalekar AD; Gillmore JD; Hawkins PN Systemic amyloidosis. Lancet 2016, 387 (10038), 2641-2654. [PubMed: 26719234] 
(8). Huang DB; Ainsworth C; Solomon A; Schiffer M Pitfalls of molecular replacement: the structure determination of an immunoglobulin light-chain dimer. Acta Crystallogr., Sect. D: Biol. Crystallogr 1996, 52, 1058-66. [PubMed: 15299564]

(9). Klimtchuk ES; Gursky O; Patel RS; Laporte KL; Connors LH; Skinner M; Seldin DC The critical role of the constant region in thermal stability and aggregation of amyloidogenic immunoglobulin light chain. Biochemistry 2010, 49 (45), 9848-57. [PubMed: 20936823]

(10). Enqvist S; Sletten K; Westermark P Fibril protein fragmentation pattern in systemic ALamyloidosis. J. Pathol 2009, 219 (4), 473-80. [PubMed: 19771564]

(11). Rennella E; Morgan GJ; Kelly JW; Kay LE Role of domain interactions in the aggregation of full-length immunoglobulin light chains. Proc. Natl. Acad. Sci. U. S. A 2019, 116 (3), 854-863. [PubMed: 30598439]

(12). Olsen KE; Sletten K; Westermark P Fragments of the constant region of immunoglobulin light chains are constituents of AL-amyloid proteins. Biochem. Biophys. Res. Commun 1998, 251 (2), 642-7. [PubMed: 9792827]

(13). Vrana JA; Gamez JD; Madden BJ; Theis JD; Bergen HR 3rd; Dogan A Classification of amyloidosis by laser microdissection and mass spectrometry-based proteomic analysis in clinical biopsy specimens. Blood 2009, 114 (24), 4957-9. [PubMed: 19797517]

(14). Radamaker L; Lin YH; Annamalai K; Huhn S; Hegenbart U; Schonland SO; Fritz G; Schmidt M; Fandrich M Cryo-EM structure of a light chain-derived amyloid fibril from a patient with systemic AL amyloidosis. Nat. Commun 2019, 10 (1), 1103. [PubMed: 30894526]

(15). Swuec P; Lavatelli F; Tasaki M; Paissoni C; Rognoni P; Maritan M; Brambilla F; Milani P; Mauri P; Camilloni C; Palladini G; Merlini G; Ricagno S; Bolognesi M Cryo-EM structure of cardiac amyloid fibrils from an immunoglobulin light chain AL amyloidosis patient. Nat. Commun 2019, 10 (1), 1269. [PubMed: 30894521]

(16). Morgan GJ; Kelly JW The Kinetic Stability of a Full-Length Antibody Light Chain Dimer Determines whether Endoproteolysis Can. Release Amyloidogenic Variable Domains. J. Mol. Biol 2016, 428 (21), 4280-4297. [PubMed: 27569045]

(17). Blancas-Mejia LM; Horn TJ; Marin-Argany M; Auton M ; Tischer A; Ramirez-Alvarado M Thermodynamic and fibril formation studies of full length immunoglobulin light chain AL-09 and its germline protein using scan rate dependent thermal unfolding. Biophys. Chem 2015, 207, 13-20. [PubMed: 26263488]

(18). Morgan GJ; Usher GA; Kelly JW Incomplete Refolding of Antibody Light Chains to NonNative, Protease-Sensitive Conformations Leads to Aggregation: A Mechanism of Amyloidogenesis in Patients? Biochemistry 2017, 56 (50), 6597-6614. [PubMed: 29200282]

(19). Eulitz M; Linke RP The precursor molecule of a V lambda II-immunoglobulin light chainderived amyloid fibril protein circulates precleaved. Biochem. Biophys. Res. Commun 1993, 194 (3), 1427-34. [PubMed: 8352801]

(20). Bellotti V; Merlini G; Bucciarelli E; Perfetti V; Quaglini S; Ascari E Relevance of class, molecular weight and isoelectric point in predicting human light chain amyloidogenicity. Br. J. Haematol 1990, 74 (1), 65-9. [PubMed: 2106912]

(21). Comenzo RL; Zhang Y; Martinez C; Osman K; Herrera GA The tropism of organ involvement in primary systemic amyloidosis: contributions of $\mathrm{Ig} \mathrm{V}(\mathrm{L})$ germ line gene use and clonal plasma cell burden. Blood 2001, 98 (3), 714-20. [PubMed: 11468171]

(22). Hoshino M; Katou H; Yamaguchi K; Goto Y Dimethylsulfoxide-quenched hydrogen/deuterium exchange method to study amyloid fibril structure. Biochim. Biophys. Acta, Biomembr 2007, 1768 (8), 1886-99.

(23). Hansen DF; Vallurupalli P; Kay LE An improved $15 \mathrm{~N}$ relaxation dispersion experiment for the measurement of millisecond time-scale dynamics in proteins. J. Phys. Chem. B 2008, 112 (19), 5898-904. [PubMed: 18001083]

(24). Korzhnev DM; Kay LE Probing invisible, low-populated States of protein molecules by relaxation dispersion NMR spectroscopy: an application to protein folding. Acc. Chem. Res 2008, 41 (3), 442-51. [PubMed: 18275162] 
(25). Tsolis AC; Papandreou NC; Iconomidou VA; Hamodrakas SJ A consensus method for the prediction of 'aggregation-prone' peptides in globular proteins. PLoS One 2013, 8 (1), e54175. [PubMed: 23326595]

(26). del Pozo Yauner L; Ortiz E; Sanchez R; Sanchez-Lopez R; Guereca L; Murphy CL; Allen A; Wall JS; Fernandez-Velasco A; Solomon A; Becerril B Influence of the germline sequence on the thermodynamic stability and fibrillogenicity of human lambda 6 light chains. Proteins: Struct., Funct., Genet 2008, 72 (2), 684-92. [PubMed: 18260098]

(27). Williams SC; Frippiat JP; Tomlinson IM; Ignatovich O; Lefranc MP; Winter G Sequence and evolution of the human germline V lambda repertoire. J. Mol. Biol 1996, 264 (2), 220-32. [PubMed: 8951372]

(28). Martin A, Chahwan R, Yar Parsa J, Scharff MD Chapter 20 - Somatic Hypermutation: The Molecular Mechanisms Underlying the Production of Effective High-Affinity Antibodies In Molecular Biology of B Cells, Second ed.; Alt FW, Andreas Radbruch TH, Reth M, Eds.; Academic Press, 2015; pp 363-388.

(29). UniProt C UniProt: a worldwide hub of protein knowledge. Nucleic Acids Res. 2019, 47 (D1), D506-D515. [PubMed: 30395287]

(30). Piehl DW; Blancas-Mejia LM; Wall JS; Kennel SJ; Ramirez-Alvarado M; Rienstra CM Immunoglobulin Light Chains Form an Extensive and Highly Ordered Fibril Involving the Nand C-Termini. ACS Omega 2017, 2 (2), 712-720. [PubMed: 28261692]

(31). Hora M; Sarkar R; Morris V; Xue K; Prade E; Harding, ; Buchner, J.; Reif, B. MAK33 antibody light chain amyloid fibrils are similar to oligomeric precursors. PLoS One 2017, 12 (7), e0181799. [PubMed: 28746363]

(32). Lecoq L; Wiegand T; Rodriguez-Alvarez FJ; Cadalbert R; Herrera GA; Del Pozo-Yauner L; Meier BH; Bockmann A A Substantial Structural Conversion of the Native Monomer Leads to in-Register Parallel Amyloid Fibril Formation in Light-Chain Amyloidosis. ChemBioChem 2019, 20 (8), 1027-1031. [PubMed: 30565364]

(33). Alexandrescu AT An NMR-based quenched hydrogen exchange investigation of model amyloid fibrils formed by cold shock protein A. Pac Symp. Biocomput 2001, 67-78. [PubMed: 11262979]

(34). Bai Y; Sosnick TR; Mayne L; Englander SW Protein folding intermediates: native-state hydrogen exchange. Science 1995, 269 (5221), 192-7. [PubMed: 7618079]

(35). Bai Y; Milne JS; Mayne L; Englander SW Primary structure effects on peptide group hydrogen exchange. Proteins: Struct., Funct., Genet 1993, 17 (1), 75-86. [PubMed: 8234246]

(36). Bai Y; Milne JS; Mayne L; Englander SW Protein stability parameters measured by hydrogen exchange. Proteins: Struct., Funct., Genet 1994, 20 (1), 4-14. [PubMed: 7824522]

(37). Vassar PS; Culling CF Fluorescent stains, with special reference to amyloid and connective tissues. Arch Pathol 1959, 68, 487-98. [PubMed: 13841452]

(38). Wall J; Schell M; Murphy C; Hrncic R; Stevens FJ; Solomon A Thermodynamic instability of human lambda 6 light chains: correlation with fibrillogenicity. Biochemistry 1999, 38 (42), 14101-8. [PubMed: 10529258]

(39). Brumshtein B; Esswein SR; Sawaya MR; Rosenberg G; Ly AT; Landau M; Eisenberg DS Identification of two principal amyloid-driving segments in variable domains of Ig light chains in systemic light-chain amyloidosis. J. Biol. Chem 2018, 293 (51), 19659-19671. [PubMed: 30355736]

(40). Kelly JW Alternative conformations of amyloidogenic proteins govern their behavior. Curr. Opin. Struct. Biol 1996, 6 (1), 11-7. [PubMed: 8696966]

(41). Dobson CM Protein misfolding, evolution and disease. Trends Biochem. Sci 1999, 24 (9), 329 32. [PubMed: 10470028]

(42). Hurle MR; Helms LR; Li L; Chan W; Wetzel R A role for destabilizing amino acid replacements in light-chain amyloidosis. Proc. Natl. Acad. Sci. U. S. A 1994, 91 (12), 5446-50. [PubMed: 8202506]

(43). Rennella E; Sekhar A; Kay LE Self-Assembly of Human Profilin-1 Detected by Carr-PurcellMeiboom-Gill Nuclear Magnetic Resonance (CPMG NMR) Spectroscopy. Biochemistry 2017, 56 (5), 692-703. [PubMed: 28052669] 
(44). Sekhar A; Rumfeldt JA; Broom HR; Doyle CM; Bouvignies G; Meiering EM; Kay LE Thermal fluctuations of immature SOD1 lead to separate folding and misfolding pathways. eLife 2015, 4, e07296. [PubMed: 26099300]

(45). Palmer AG 3rd; Kroenke CD; Loria JP Nuclear magnetic resonance methods for quantifying microsecond-to-milli-second motions in biological macromolecules. Methods Enzymol 2001, 339, 204-38. [PubMed: 11462813]

(46). Morgan GJ; Yan NL; Mortenson DE; Rennella E; Blundon JM; Gwin RM; Lin CY; Stanfield RL; Brown SJ; Rosen H; Spicer TP; Fernandez-Vega V; Merlini G; Kay LE; Wilson IA; Kelly JW Stabilization of amyloidogenic immunoglobulin light chains by small molecules. Proc. Natl. Acad. Sci. U. S. A 2019, 116 (17), 8360-8369. [PubMed: 30971495]

(47). Capra JA; Singh M Predicting functionally important residues from sequence conservation. Bioinformatics 2007, 23 (15), 1875-82. [PubMed: 17519246]

(48). Brack C; Hirama M; Lenhard-Schuller R; Tonegawa S A complete immunoglobulin gene is created by somatic recombination. Cell 1978, 15 (1), 1-14. [PubMed: 100225]

(49). Mirny LA; Shakhnovich EI Universally conserved positions in protein folds: reading evolutionary signals about stability, folding kinetics and function. J. Mol. Biol 1999, 291 (1), 177-96. [PubMed: 10438614]

(50). Scaviner D; Barbie V; Ruiz M; Lefranc MP Protein displays of the human immunoglobulin heavy, kappa and lambda variable and joining regions. Exp. Clin. Immunogenet 1999, 16 (4), 234-40. [PubMed: 10575277]

(51). Zhang YZ; Paterson Y; Roder H Rapid amide proton exchange rates in peptides and proteins measured by solvent quenching and two-dimensional NMR. Protein Sci. 1995, 4 (4), 804-14. [PubMed: 7613478]

(52). Sattler M; Schleucher J; Griesinger C Heteronuclear multidimensional NMR experiments for the structure determination of proteins in solution employing pulsedfield gradients. Prog. Nucl Magn. Reson. Spectrosc 1999, 34, 93-158.

(53). Jiang B; Yu B; Zhang X; Liu M; Yang DA (15)N CPMG relaxation dispersion experiment more resistant to resonance offset and pulse imperfection. J. Magn. Reson 2015, 257, 1-7. [PubMed: 26037134]

(54). Mulder FA; Skrynnikov NR; Hon B; Dahlquist FW; Kay LE Measurement of slow (micros-ms) time scale dynamics in protein side chains by (15)N relaxation dispersion NMR spectroscopy: application to Asn and Gln residues in a cavity mutant of T4 lysozyme. J. Am. Chem. Soc 2001, 123 (5), 967-75. [PubMed: 11456632]

(55). Korzhnev DM; Salvatella X; Vendruscolo M; Di Nardo AA; Davidson AR; Dobson CM; Kay LE Low-populated folding intermediates of Fyn SH3 characterized by relaxation dispersion NMR. Nature 2004, 430 (6999), 586-90. [PubMed: 15282609]

(56). Santoro MM; Bolen DW Unfolding free energy changes determined by the linear extrapolation method. 1. Unfolding of phenylmethanesulfonyl alpha-chymotrypsin using different denaturants. Biochemistry 1988, 27 (21), 8063-8. [PubMed: 3233195]

(57). Hernandez-Santoyo A; del Pozo Yauner L; Fuentes-Silva D; Ortiz E; Rudino-Pinera E; SanchezLopez R; Horjales E; Becerril B; Rodriguez-Romero A A single mutation at the sheet switch region results in conformational changes favoring lambda6 light-chain fibrillogenesis. J. Mol. Biol 2010, 396 (2), 280-92. [PubMed: 19941869] 
A

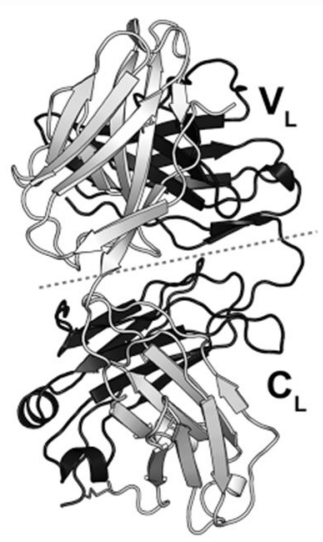

B
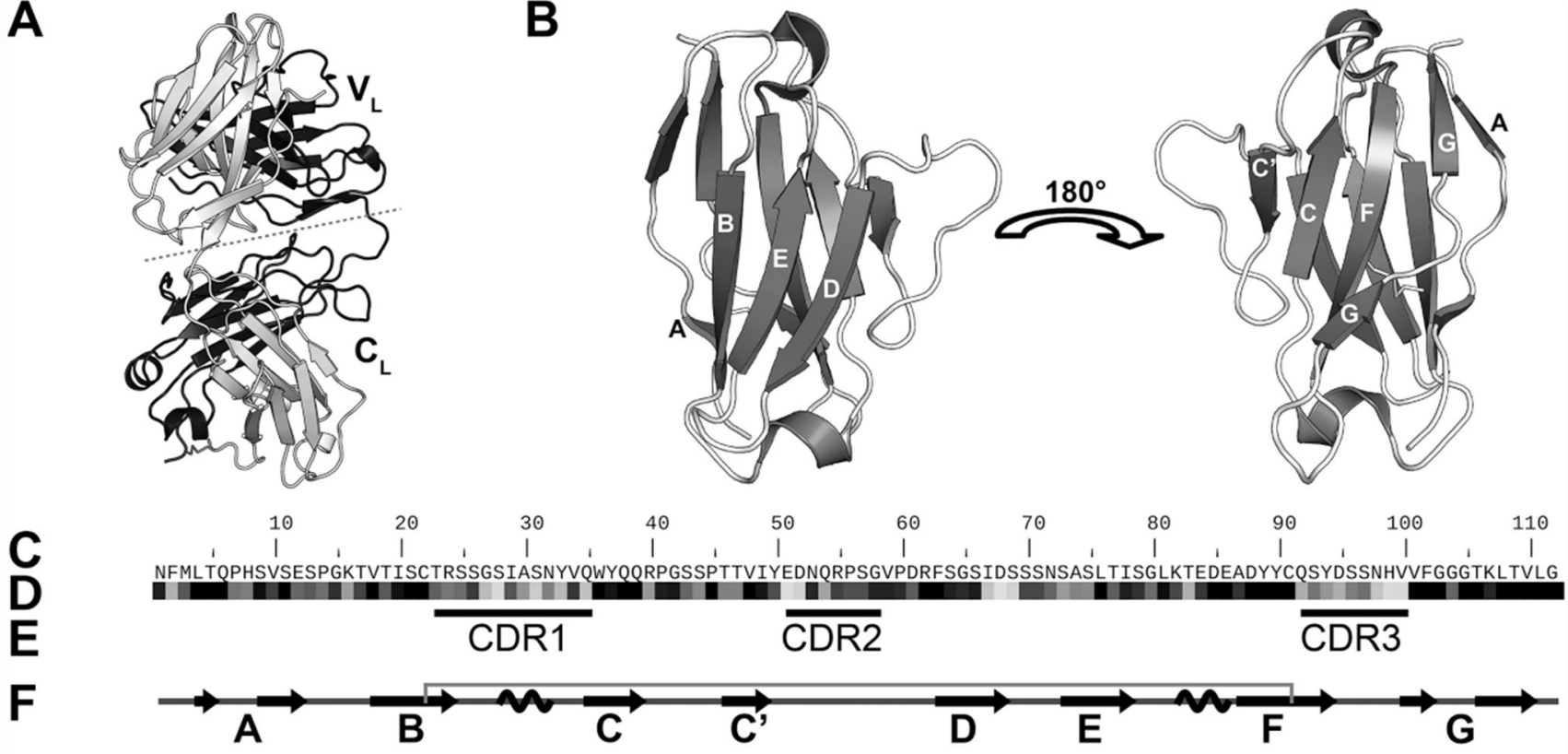

G

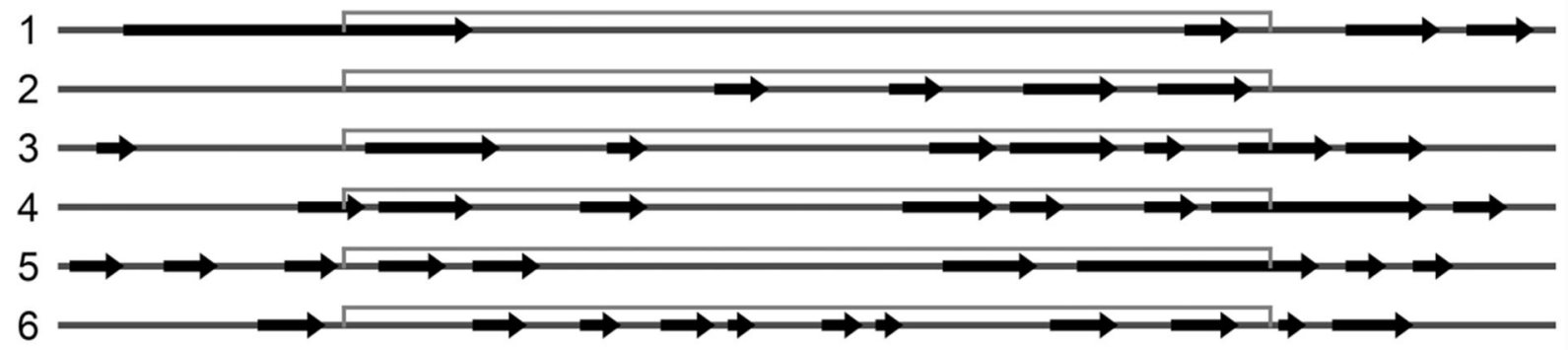

H 1.0
$\frac{I(2 \mathrm{~h})}{I(0 \mathrm{~h})}$

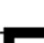

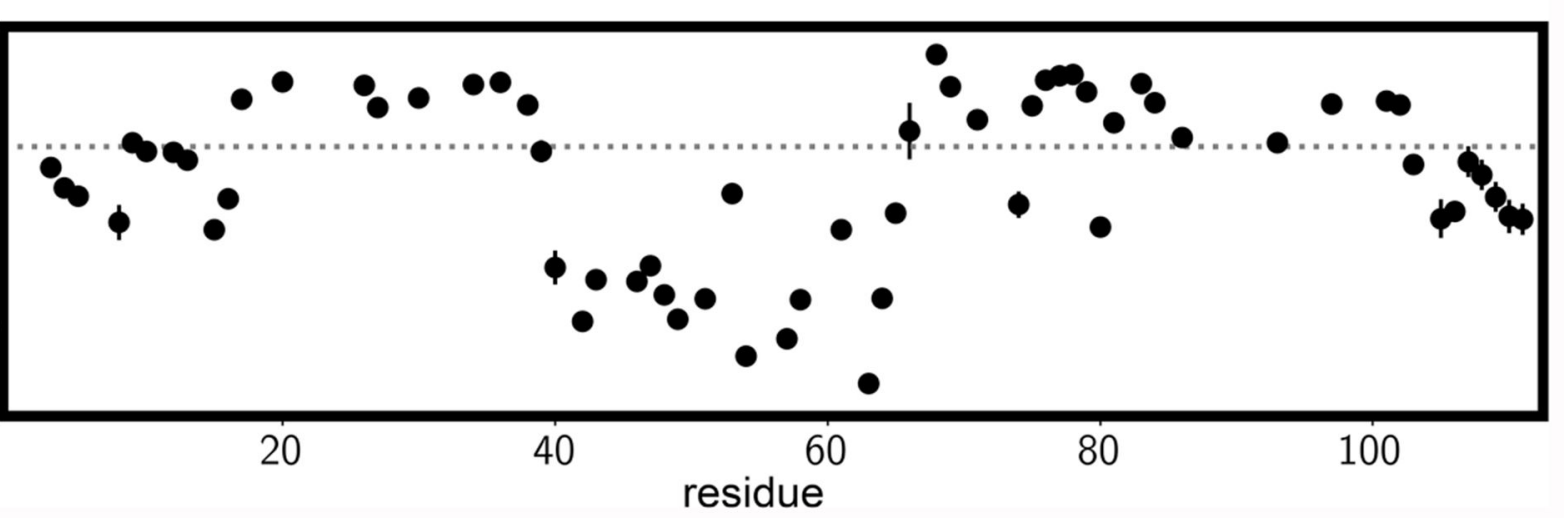

Figure 1.

Structural propensities of $\mathrm{V}_{\mathrm{L}}$ domains in native and fibrillar states. (A) 3D structure of the CLE full-length $\lambda$ light-chain dimer (PDB $1 \mathrm{LIL}^{8}$ ). (B) 3D structure of the 6aJL2- $\mathrm{V}_{\mathrm{L}}$ domain (PDB $2 \mathrm{~W}_{0} \mathrm{~K}^{57}$ ). (C) Primary amino acid sequence of $6 \mathrm{aJL2}-\mathrm{V}_{\mathrm{L}}$. (D) Sequence conservation within the $\lambda$ immunoglobulin $\mathrm{V}_{\mathrm{L}}$ domain family using a grayscale from 0 (very variable position, white) to 1 (very conserved, black). (E) Positions of complementarity-determining regions, CDRs, that directly contact antigens. (F) Secondary structure of the native 6aJL2$\mathrm{V}_{\mathrm{L}}$ domain. Arrows, coils, and straight lines correspond to $\beta$-strands, $a$-helices, and random 
coils, respectively. The gray line above the secondary structure diagram connects the Cys residues that form a disulfide. $(\mathrm{G})$ Location of $\beta$-strands in $\mathrm{V}_{\mathrm{L}}$ amyloid fibrils as reported by several studies: 1, AL-09 $\mathrm{V}_{\mathrm{L}}$ fibrils studied by ssNMR; ${ }^{30} 2$, MAK33 $\mathrm{V}_{\mathrm{L}}$ fibrils (ssNMR); 31 3 and 4, polymorphs $A$ and $B$ for R24G 6aJL2- $\mathrm{V}_{\mathrm{L}}$ fibrils characterized by ssNMR; ${ }^{32} 5$, $\lambda$ V6-57 fibrils extracted from a patient (cryo-EM) $;{ }^{15} 6, \lambda \mathrm{V} 1-44$ fibrils extracted from a patient (cryo-EM) ${ }^{14}(\mathrm{H})$ Decrease in intensities of amide correlations as measured in ${ }^{1} \mathrm{H}$, ${ }^{15} \mathrm{~N}$ HSQC spectra after $2 \mathrm{~h}$ of hydrogen exchange of $6 \mathrm{aJL} 2-\mathrm{V}_{\mathrm{L}}$ fibrils $\left(23^{\circ} \mathrm{C}\right)$; the gray dashed line indicates a threshold of 0.8 . 

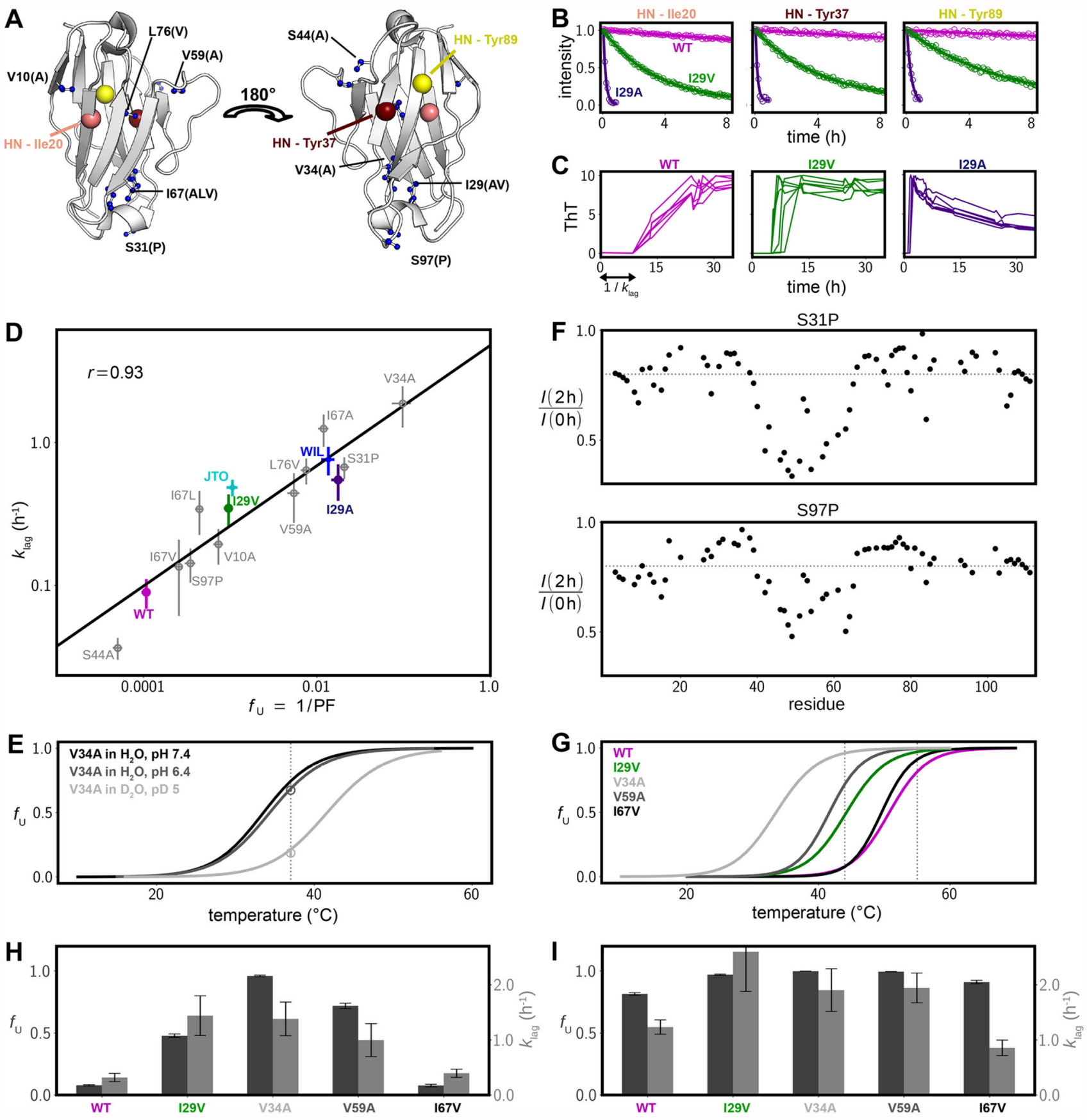

Figure 2.

Thermodynamic stability and aggregation propensities for a series of $6 \mathrm{aJL} 2-\mathrm{V}_{\mathrm{L}}$ mutants. (A) Positions of the mutated residues plotted as blue spheres on the 3D structure of the domain (PDB $2 \mathrm{w}_{0 \mathrm{k}}{ }^{57}$ ) using a ball and stick representation. New amino acids introduced by mutation are indicated by the single-letter code in brackets. The three large spheres delineate the amide groups whose solvent hydrogen exchange decay is shown in panel B. (B) Hydrogen/deuterium exchange time profiles for three amide groups of selected $6 \mathrm{aJL} 2-\mathrm{V}_{\mathrm{L}}$ variants. (C) Kinetics of aggregation as monitored by ThT fluorescence for three selected 
6aJL2- $\mathrm{V}_{\mathrm{L}}$ variants; six traces are shown in each subpanel. The decrease in fluorescence for the I29A variant at long times is likely because fibrils become larger and less accessible to ThT or due to self-quenching. (D) Correlation between the estimated fraction of fully unfolded protein $f_{\mathrm{U}}$ and the inverse duration of the lag phase, $k_{\text {lag }}$, shown on a $\log -\log$ scale. Values of $f_{\mathrm{U}}$ were calculated as the reciprocal of the average protection factor for the most protected residues (maroon-colored residues in Figure S1), with uncertainties obtained from the standard deviation of these values. Errors in $k_{\text {lag }}$ rates are based on at least six repetitions of the ThT aggregation assays. (E) Thermal melting curves for V34A for several conditions, as measured by intrinsic fluorescence (lines) and solution NMR (circles). The NMR-based $f_{\mathrm{U}}$ value in $\mathrm{D}_{2} \mathrm{O}$ at $\mathrm{pH} 5,37^{\circ} \mathrm{C}$ was obtained from hydrogen exchange measurements, while the $f_{\mathrm{U}}$ value at $\mathrm{pH} 6.4$ and in $\mathrm{H}_{2} \mathrm{O}\left(\mathrm{NMR}, 37^{\circ} \mathrm{C}\right.$ ) was calculated from the volumes of the native- and unfolded-state peaks for G112 in ${ }^{1} \mathrm{H},{ }^{15} \mathrm{~N}$ HSQC spectra. The dashed vertical line at $37{ }^{\circ} \mathrm{C}$ indicates the temperature at which the NMR experiments were performed. (F)

Decrease in amide peak intensities after $2 \mathrm{~h}$ of hydrogen exchange of.S31P and S97P 6aJL2$\mathrm{V}_{\mathrm{L}}$ fibrils $\left(23^{\circ} \mathrm{C}\right)$; the gray dashed lines indicate a value of 0.8 . Similar profiles are obtained for the WT domain (Figure $1 \mathrm{H}$ ). $(\mathrm{G})$ Thermal melting curves for five $6 \mathrm{aJL2}-\mathrm{V}_{\mathrm{L}}$ variants in $\mathrm{H}_{2} \mathrm{O}$ at $\mathrm{pH}$ 7.4. Dashed vertical lines are positioned at 44 and $55^{\circ} \mathrm{C}$ (see panels $\mathrm{H}$ and $\mathrm{I}$ ). (H) Bar plots of $f_{\mathrm{U}}$ values (dark gray, left $y$-axis) and $k_{\text {lag }}$ (pale gray, right $y$-axis) at $44^{\circ} \mathrm{C}$. (I) As in panel $\mathrm{H}$, but at $55^{\circ} \mathrm{C}$. 
A

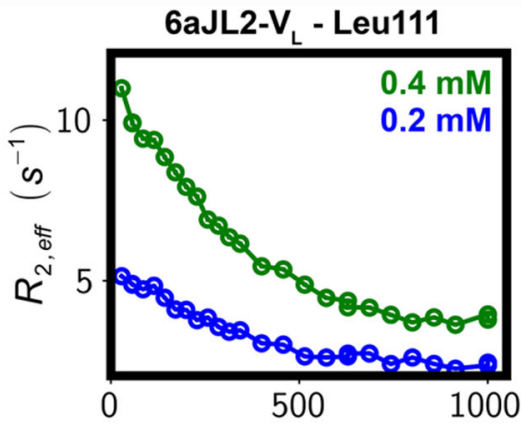

B
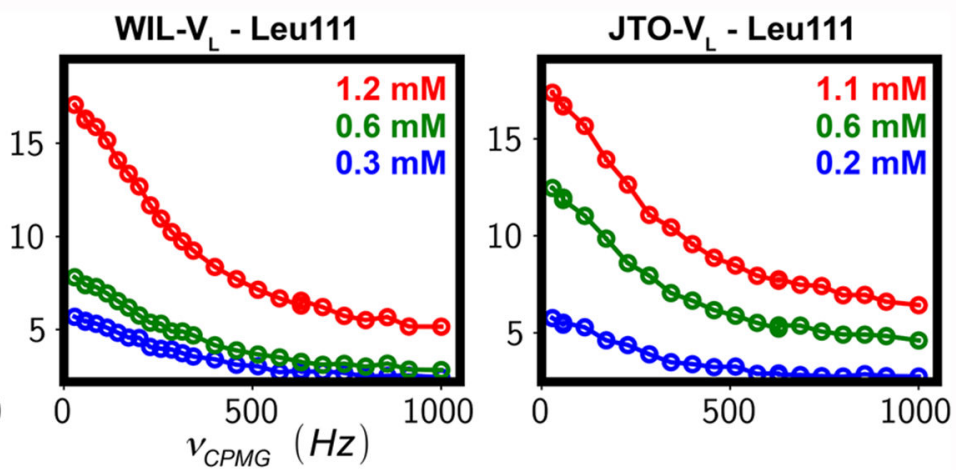

80

100

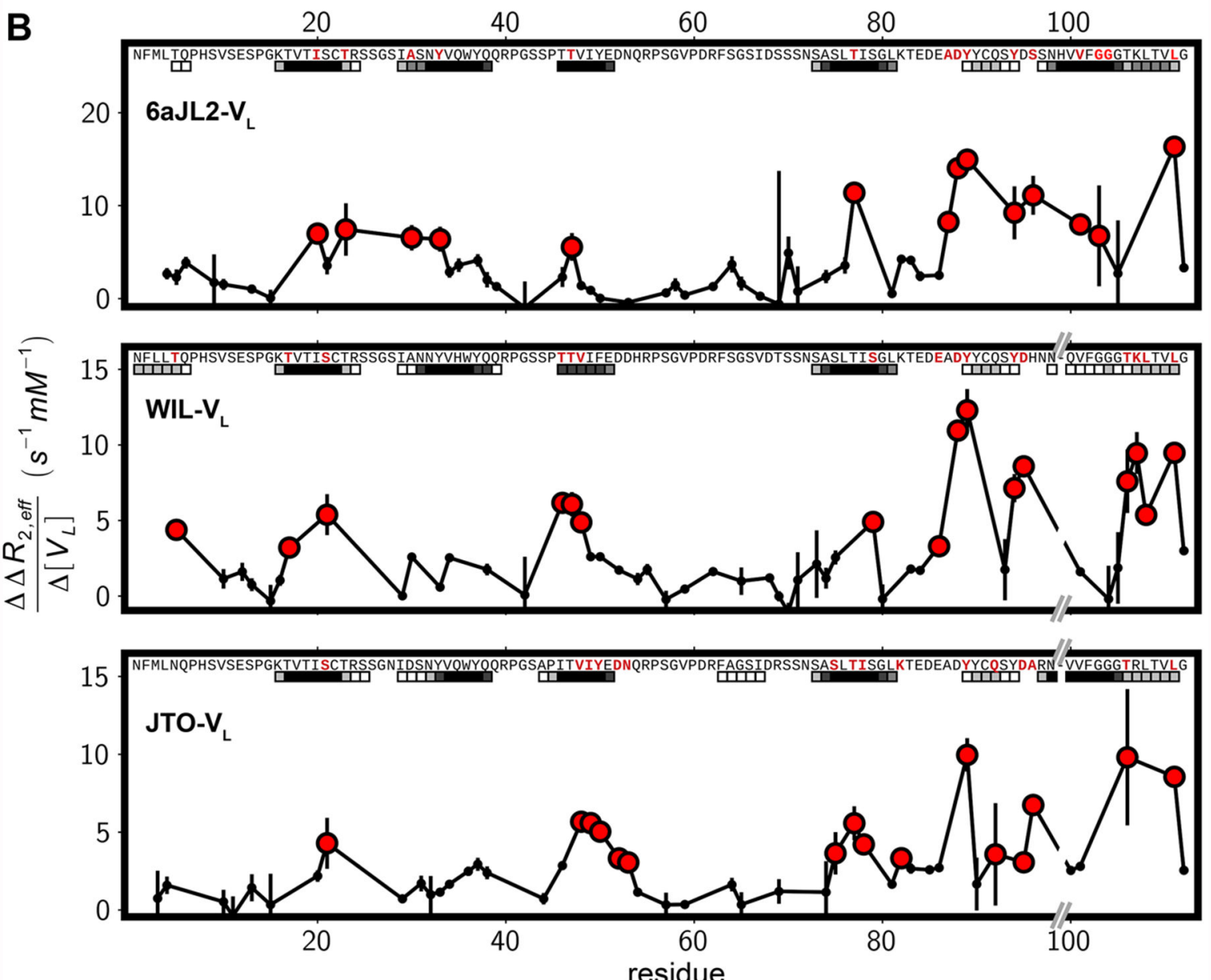

Figure 3.

Oligomerization from the unfolded states of the $\lambda \mathrm{V} 6-57 \mathrm{~V}_{\mathrm{L}}$ domains probed by ${ }^{15} \mathrm{~N}$ CPMG NMR. (A) ${ }^{15} \mathrm{~N}$ CPMG profiles for Leu111 of 6aJL2, WIL, and JTO- $\mathrm{V}_{\mathrm{L}}$ domains at the indicated protein concentrations. (B) Concentration dependence of $\Delta R_{2, \text { eff }}$, the difference in $R_{2, \text { eff }}$ rates at minimum and maximum $v_{\mathrm{CPMG}}$ values, for individual amide groups of three $\lambda \mathrm{V} 6-57 \mathrm{~V}_{\mathrm{L}}$ domains. Red circles indicate high concentration dependence, i.e., values higher than $5 \mathrm{~s}^{-1} \mathrm{mM}^{-1}$ (6aJL2) or $3 \mathrm{~s}^{-1} \mathrm{mM}^{-1}$ (WIL and JTO- $\mathrm{V}_{\mathrm{L}}$ ). Residue-specific

AMYLPRED $2^{25}$ predictions are shown as squares at the top of each panel with a consensus 
score shown in grayscale between 2 (white) and 6 or higher (black), where higher values indicate an increasing propensity to aggregate. Note that there is a single-residue deletion at position 99 for WIL and JTO in comparison to $6 \mathrm{aJL2}-\mathrm{V}_{\mathrm{L}}$. Lines between experimental points are included to guide the eye. 

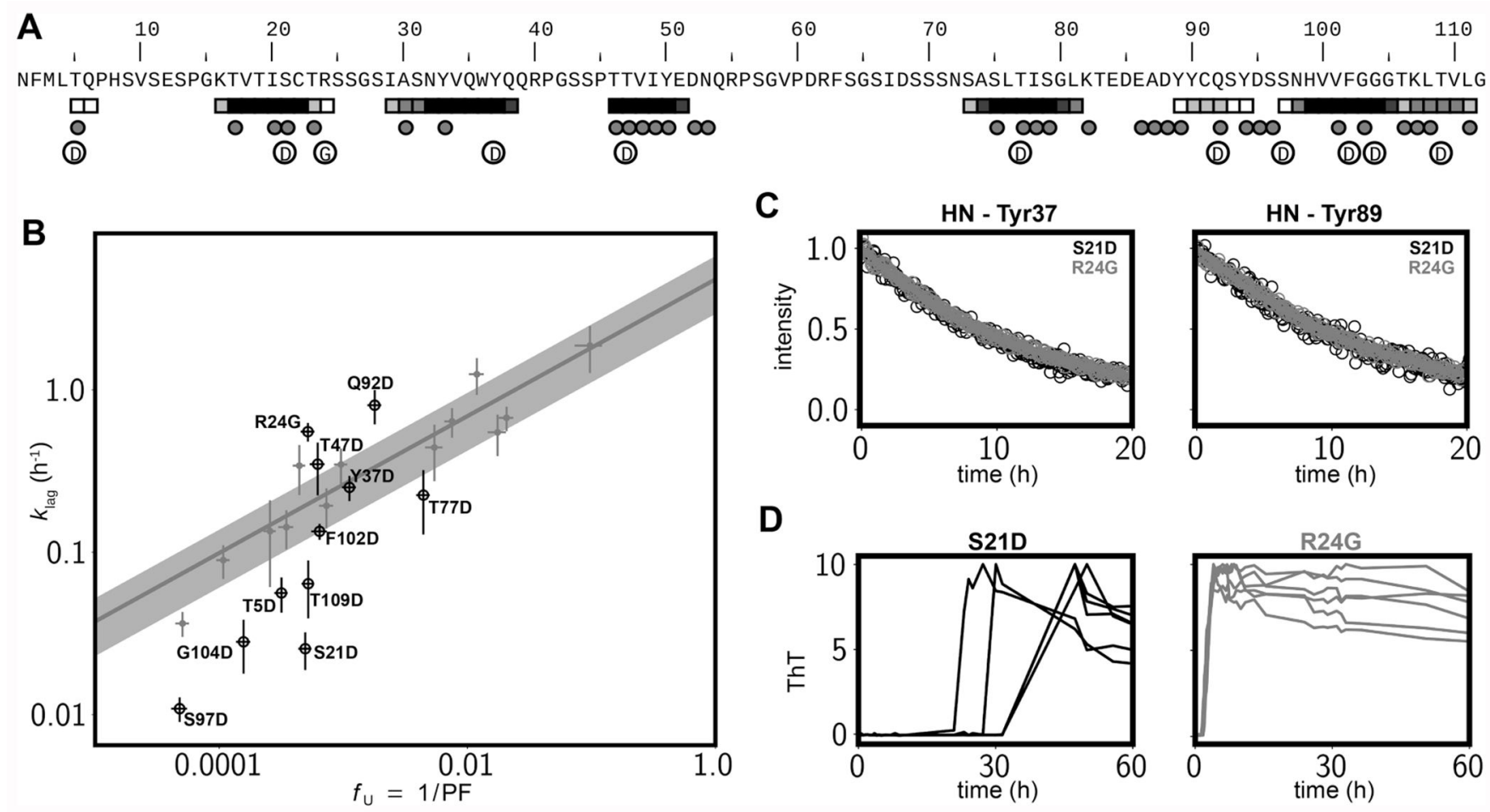

D
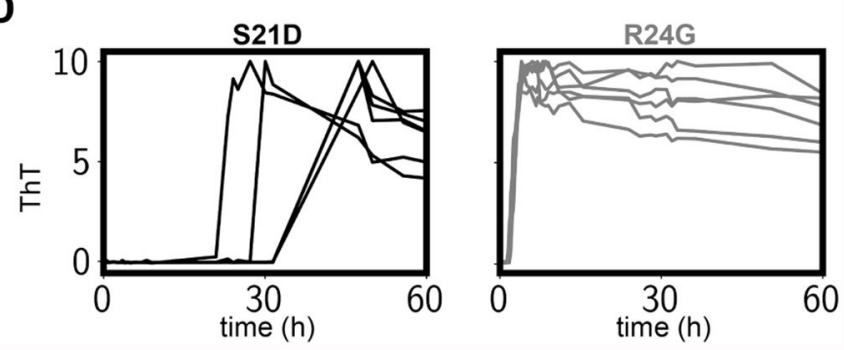

Figure 4.

Mutations in polymerization-prone regions modulate aggregation kinetics. (A) Locations of the introduced mutations, Asp or Gly, in the sequence of the $\lambda \mathrm{V} 6-57 \mathrm{~V}_{\mathrm{L}}$ domain are indicated by circled D or G. AMYLPRED $2^{25}$ predictions (squares) and residues with a high concentration dependence of $\Delta R_{2 \text {,eff }}$ in any of the $\lambda \mathrm{V} 6-57 \mathrm{~V}_{\mathrm{L}}$ domains examined (spheres), as defined in the caption of Figure 3, are also shown. (B) Correlation, on a log-log scale, between $f_{\mathrm{U}}$ and $k_{\mathrm{lag}}$, showing a significant deviation from the fitted curve of Figure $2 \mathrm{D}$ (gray line, shaded area indicates the standard error in $k_{\text {lag }}$ values; see Materials and Methods) for several mutants in aggregation-prone regions. Unlabeled gray circles are the data points for the conservative mutations considered in Figure 2D. Data points from mutants where a polar group is either introduced (10 mutations to Asp) or removed (1 mutation to Gly) in hotspot regions are indicated by labeled black circles. (C) Solvent hydrogen/deuterium exchange time profiles for two representative slowly exchanging amide groups from S21D and R24G 6aJL2- $\mathrm{V}_{\mathrm{L}}$ mutants. (D) Kinetics of aggregation monitored by ThT fluorescence for S21D and R24G 6aJL2- $\mathrm{V}_{\mathrm{L}}$; six traces are shown in each subpanel. 